of delayed hypersensitivity skin reaction sites. Cell. Immunol. 9: 363 (1973).

6. Documenta Geigy. Scientific tables 6th edition. p. 32 (Geigy Pharmaceuticals Summit, 1968).

7. Eife, R. F., Eife, G., August, C. S., Kuhre, W. L., and Staehr-Johanse, K.: Lymphotoxin production and blast cell transformation by cord blood lymphocytes: dissociated lymphocyte function in newborn infants. Cell. Immunol., 14: 435 (1974).

8. Miller, M. E. Host defenses in the human neonate. page 51. (Grune and Stratton, Inc. New York, 1978).

9. Hahn, T., Levin, S., and Handzel, Z. T.: Production of immune and viral interferon by lymphocytes of newborn infants. Isr. J. Med. Sci., 16: 33 (1980).

10. Handzel, Z. T., Levin, S., Dolphin, Z., Schlesinger, M., Hahn, T., Altman, Y., Schechter, B., Shneyour, A., and Trainin, N.: Immune competence of newborn lymphocytes. Pediatrics, 65: 491 (1980).

11. Kretschmer, R. R., Stewardson, P. B., Papierniak, C. K., and Gotoff, S. P.: Chemotactic and bactericidal capacities of human newborn monocytes. J. Immunol., 117: 1303 (1976)

12. Muller, M. R., Lazary, S., and Hitzig, W. H.: Production of migration inhibitory factor and blast cell transformation by cord blood lymphocytes. Int. Arch Allergy Appl. Immunol., 50: 593 (1976).

13. Postlethwaite, A. E. and Snyderman, R.: Characterization of chemotactic activity produced in vivo by a cell-mediated immune reaction in the guinea pig. $\mathrm{J}$. Immunol., 114: 274 (1975).
14. Raghunathan, R., Miller, M. E., Everett, S., and Leake, R. D.: Phagocyte chemotaxis in the perinatal period. J. Clin. Immunol., 2: 242 (1982).

15. Snyderman, R., Meadows, L., and Amos, D. B.: Characterization of human chemotactic lymphokine production induced by mitogens and mixed leukocyte reactions using a new microassay. Cell Immunol., 30: 225 (1977)

16. Stiehm, E. R., Winter, H. S., and Bryson, Y. J.: Cellular (T cell) immunity in the human newborn. Pediatr. Suppl., 64: 814 (1979).

17. Wara, D. W. and Barrett, D. J.: Cell-mediated immunity in the newborn: clinica aspects. Pediatr. Suppl., 64: 822 (1979).

18. Requests for reprints should be addressed to: Dr. Margaret A. Keller, Department of Pediatrics-E6, Harbor-UCLA Medical Center, 10000 West Carson Street, Torrance, CA 90509.

19. This study was supported in part by a Young Investigator Grant from the California Research and Medical Education Fund of the American Lung Association of California, a Public Health Service Young Investigator Research Grant (AI 17124-01) from the National Institute of Allergy and Infectious Diseases, and by NIH-GCRC Grant RR00425. The authors also wish to thank Mr. Edward Smith, Dr. Rukmani Raghunathan and Dr. Michael Miller for their careful review of the Manuscript and Ms. Elaine Praskins for secretarial assistance.

20. Received for publication August 26, 1982

21. Accepted for publication March 1, 1983.

\title{
Failure of High Intensity Auditory Stimuli to Affect Behavioral Arousal in Children during the First Sleep Cycle
}

\author{
K. BUSBY AND R. T. PIVIK ${ }^{(43)}$ \\ Department of Psychiatry and School of Psychology, University of Ottawa, Ottawa, Ontario, Canada
}

\section{Summary}

Behavioral and physiologic indices of arousal to auditory stimuli were examined during the first cycle of sleep in 8-12-year-old hyperactive children and nonhyperactive controls. No behavioral responses or sustained awakenings were obtained for any child during the first cycle of sleep to stimuli at intensities up to $123 \mathrm{~dB}$ sound pressure level $r e 0.0002$ dynes $/ \mathrm{cm}^{2}$ ), i.e., at intensities more than $90 \mathrm{~dB}$ above waking threshold values. Half of the arousal attempts in stage 2 and a quarter of those in stage 4 elicited a partial or momentary physiologic arousal response (i.e., EEG desynchronization and/or change in skin potential response or respiratory activity rates). These arousals were shortlived, with the subjects returning to sleep even with continuing or increased stimulus intensity. Neither the incidence of partial arousals nor the associated threshold intensities differentiated subject groups. Although increased skin potential response activity and decreased respiratory rates were observed during sleep relative to wakefulness, and a predominance of skin potential response activity was noted in stage 4 sleep, no significant differences in frequency (rate/min) of autonomic response measures were obtained when rates before and during auditory stimulation were compared.

\section{Abbreviations}

AATs, auditory arousal thresholds

NREM, non-REM
REMP, rapid eye movement period

SPL, sound pressure level

SPR, skin potential response

$\mathrm{W}$, wakefulness

Normal sleep is punctuated by arousals of varied intensity and duration, which ultimately result in sleep termination and extended wakefulness. This awakening response is one of the most dramatic yet least understood behaviors associated with sleep. Although this response occurs spontaneously i.e., in the absence of disruptive external stimuli, it has been largely through the application of external stimuli in studies determining arousal thresholds from sleep that this process has been examined. These studies have considered varying degrees of arousal, ranging from subawakening variations in physiologic measures to indices of more complete arousal, such as specific behavioral responses indicating stimulus awareness $(2,16,22,27)$, and have established the relevance of several stimulus (modality, intensity, and significance) and state (sleep stage and time of night) variables to the awakening process $(18,24,26,39,40,41)$. In man, these studies have been carried out almost exclusively in adults, and those which have involved children $(20,31,33)$ have not assessed the stimulus parameters required to elicit a behavioral response. The present study provides the first such data and includes the evaluation of physiologic and behavioral correlates of AATs during the first sleep cycle in normal and hyperactive children. The latter 
comparison group was included because it was thought that the postulated dysfunction of arousal mechanisms in hyperkinesis, which is not reflected in marked deviations from normal sleep patterning or duration in these children $(5,9,11,19,35,37)$, might be evident in arousal threshold measures from sleep. Because data analyses revealed the absence of group differences with respect to either AAT values or physiologic and behavioral measures of arousal (see waking and nocturnal threshold results below), group data were combined for this report.

\section{MATERIALS AND METHODS}

Twelve nonmedicated male children (five hyperactives and seven normal controls: mean age $=10.3$ years, S.D. $=1.5$ ) were subjects for this investigation. These children were recruited from the local school population. Hyperactivity diagnoses were based upon positive indications ( $>15$ on hyperactivity index) on Conners Parent and Teacher behavioral rating scales $(6,7)$, as well as the persistent or recurrent presence of the following symptomatology: motor restlessness, distractibility, short attention span, impulsiveness, labile emotions, and poor academic performance. All subjects underwent audiometric examinations to ensure normal hearing. Presleep auditory thresholds were determined in the sleep laboratory using the method of limits. This procedure involved presenting the tones $(1500 \mathrm{~Hz})$ via earphone insert first in decreasing intensity (descending series) until the subject no longer responded and then increasing intensity (ascending series) until responding resumed. The average of several descending and ascending series established the threshold. Presleep threshold values for hyperactive and control children using this method (hyperactives, $\overline{\mathrm{X}}=$ $30.1 \pm 6.4 \mathrm{~dB}$ SPL; controls, $\bar{X}=29.8 \pm 7.2 \mathrm{~dB}$ SPL) did not differ significantly $(t=0.11)$. Subjects spent three consecutive nights in the sleep lab where EEG $\left(\mathrm{C}_{3} / \mathrm{A}_{2}\right)$, EOG (bipolar placements for detection of horizontal and vertical eye movements), EMG (facial muscle), SPR (spontaneous skin potential responses recorded from the medial phalanx of left middle finger referenced to left forearm), and respiratory (chest strain gauge) activities were continuously monitored. Recording rooms were sound-attenuated, electrically shielded, and temperature and humidity controlled. Preceding sleep on each night, instructions regarding the experimental task were reviewed. The first night was an adaptation night during which subjects slept undisturbed. On nights 2 and 3, AAT measurements were obtained to tones delivered via earphone insert during sleep stages 2 and 4 (29) within the first cycle of sleep (sleep onset to first REMP onset, $\overline{\mathrm{X}}$ cycle length $=123.3$ min., S.D. $=29.5$ ). After sleep onset, subjects were allowed a minimum of 5-10 min of uninterrupted sleep before stimulation began, and attempts to determine AATs were made throughout the first sleep cycle. Auditory stimuli $(1500 \mathrm{~Hz}$ tones of $3 \mathrm{sec}$ duration, alternating $3 \mathrm{sec}$ "on," $3 \mathrm{sec}$ "off") were delivered in an ascending series of increasing intensity (2-5 dB increments) beginning at waking threshold values. To indicate arousal from sleep, subjects were instructed to press a hand-held button three times and say, "I'm awake" when they became aware of the tone. Stateand stimulus-associated variations in autonomic activity were determined for SPR and respiration from 1-min presleep samples and from 1-min periods before and during stimulation. Each pen deflection of $\geq 1 \mathrm{~mm}(100 \mu \mathrm{V}$ potential change with amplifier impedance $=1$ megohm) was scored as a SPR response (17).

\section{RESULTS}

No behavioral responses or sustained awakenings were obtained for any child during the first cycle of sleep to stimuli at intensities up to $123 \mathrm{~dB}$ (SPL re 0.0002 dynes $/ \mathrm{cm}^{2}$ ) i.e., at intensities more than $90 \mathrm{~dB}$ above waking threshold values. Stimulus intensity was not raised above this value because further increases could be damaging to the auditory system (34). Figure 1 illustrates an arousal attempt during stage 4 sleep which failed to evoke even autonomic responses at the highest stimulus intensity. Of the total attempts to awaken subjects $(n=61), 13$ of $26(50 \%)$ attempts in stage 2 , and 9 of $35(25.7 \%)$ attempts in stage 4 elicited a partial or momentary physiologic arousal response (i.e., EEG desynchronization and/or change in SPR or respiratory activity rate). The mean intensity levels required to elicit these nonsustained arousals were 105.6 dB SPL (S.D. = 17.4) for stage 2 and 106.9

\section{STAGE 4}

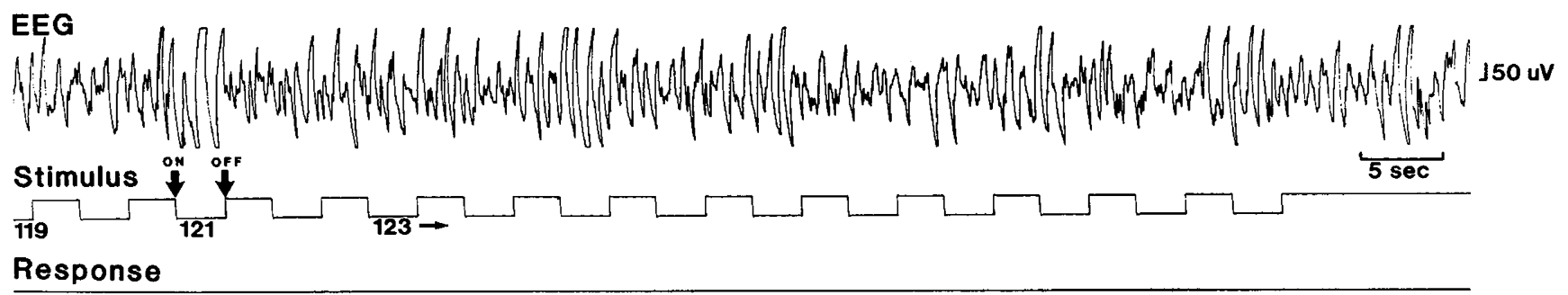

\section{HEOG}

VEOG

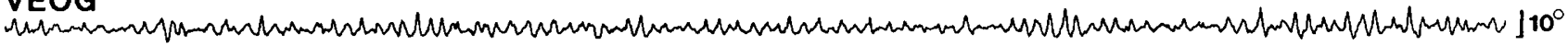

\section{EMG}

\section{SPR}

\section{Respiration}

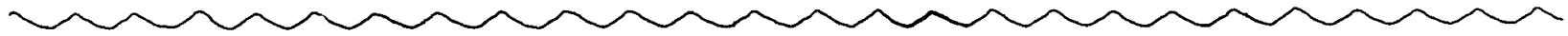

Fig. 1. A typical arousal attempt during stage 4 sleep showing a failure to elicit cortical EEG desynchronization or autonomic nervous system responses during prolonged auditory stimulation at the highest intensity level $(123 \mathrm{~dB})$. Intensity levels (i.e., 119, 121, 123 dB) are indicated beneath pulse deflections on stimulus channel. See "Materials and Methods" for explanation of abbreviations used in Figures 1 and 2. 
STAGE 2 AROUSAL

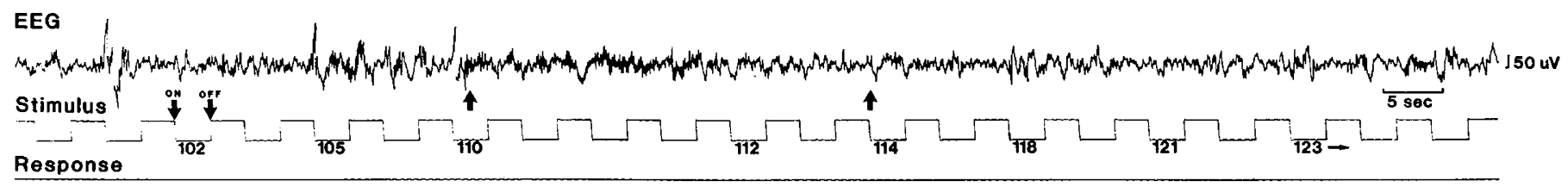

\begin{tabular}{|c|c|c|c|}
\hline \multicolumn{4}{|l|}{ VEOG } \\
\hline \multicolumn{4}{|l|}{ SPR } \\
\hline \multicolumn{4}{|l|}{ Respiration } \\
\hline \multicolumn{4}{|c|}{$\begin{array}{l}\text { Fig. 2. An example of a nonsustained, partial arousal during stage } 2 \\
\text { indicated by muscle artifact obscuring EEG activity, eye movements, ele } \\
\text { at increasing intensity. No behavioral response occurred and the subject }\end{array}$} \\
\hline \multicolumn{4}{|c|}{$\begin{array}{c}\text { Table 1. Variations (mean, S.D.) in stimulus-associated skin } \\
\text { potential responses (SPR) and respiratory rates across recording } \\
\text { conditions }\end{array}$} \\
\hline & \multicolumn{3}{|c|}{ Condition } \\
\hline Measure & W & Stage 2 & Stage 4 \\
\hline \multicolumn{4}{|l|}{ SPR (rate/min) } \\
\hline Pre-stimulation & $2.5(2.4)$ & $4.6(4.7)$ & $8.1(3.4)$ \\
\hline Stimulation & & $4.8(4.5)$ & $7.4(4.0)$ \\
\hline \multicolumn{4}{|c|}{ Respiration (rate/min) } \\
\hline Pre-stimulation & $21.7(3.3)$ & $18.5(3.0)$ & $18.9(2.5)$ \\
\hline Stimulation & & $18.3(3.2)$ & $18.6(3.0)$ \\
\hline
\end{tabular}

dB SPL (S.D. = 13.8) for stage 4. These arousals were shortlived, with the subjects returning to sleep even with continuing or increased stimulus intensity (Fig. 2). Neither the incidence of partial arousals (hyperactives 37\%; controls 29.4\%; $\chi^{2}=0.397$, non-significant) nor the associated threshold intensities (hyperactives, $\overline{\mathrm{X}}=102.9 \pm 19.1 \mathrm{~dB}$ SPL; controls, $\overline{\mathrm{X}}=109.1 \pm 14.4 \mathrm{~dB}$ $\mathrm{SPL} ; \mathrm{t}=0.85$, non-significant) differentiated subject groups. If arousal threshold differences do exist during sleep between hyperactive and nonhyperactive children, such differences are not apparent during the first sleep cycle.

No significant differences in frequency (rate/min) of autonomic response measures were obtained when rates before and during auditory stimulation were compared; however, spontaneous SPR rates differed between wakefulness and sleep and between sleep stages $\left(\mathrm{W}<\mathrm{S}_{2}, P<0.01 ; \mathrm{W}<\mathrm{S}_{4}, P<0.01 ; \mathrm{S}_{4}>\mathrm{S}_{2}, P<0.01\right.$ ). Respiratory rates declined during sleep relative to wakefulness ( $P$ $<0.01$ ), but did not vary across sleep stages. Table 1 presents summary data for the autonomic measures during stimulation and non-stimulation conditions.

\section{DISCUSSION}

On the basis of results from previous investigations of arousal threshold measures in adults and inferential data from studies in children $(4,22,33)$, high threshold values were expected in the first sleep cycle in our subjects. The impossibility of inducing behavioral arousal during the initial two hours of sleep was completely unexpected. Not only was there a failure to elicit behavioral arousal, but physiologic activation in the form of either cortical EEG desynchronization or increased autonomic excitability was severely diminished as well. Only $36 \%$ of all arousal attempts eventuated in even transient indications of physiologic arousal, and these required stimulus intensities exceeding waking auditory threshold levels by more than $75 \mathrm{~dB}$ SPL.

The methodology employed in this investigation excludes explanations for the observed effects based upon defective hearing (waking auditory thresholds were normal), ineffective stimulus delivery (earphone insert ensured reliable stimulus delivery), or habituation (except at maximum intensity, stimulus intensity levels were maintained for only 2 consecutive stimuli). Furthermore, replication in this study of previously observed state-associated changes in autonomic activity, including increased SPR activity and decreased respiratory rates during sleep relative to wakefulness, and a predominance of SPR activity in stage 4 sleep, attests to the reliability of recording procedures and normal physiologic responsivity of the subjects.

Among those factors that may influence externally initiated arousals from sleep, the importance of stimulus significance is generally recognized and is of potential relevance to interpretation of the present data. It could be argued, for example, that $1500 \mathrm{~Hz}$ tones are meaningless stimuli not warranting attention and are, therefore, unlikely to elicit arousal. This explanation might be plausible for low intensity stimuli, but the higher intensity stimuli utilized in this study should acquire significance because of their irritating, even nociceptive qualities.

The persistence of sleep in the presence of such stimuli is congruent with other data indicating enhancement of processes minimizing reactivity and behavioral responsiveness during the first cycle of sleep. For example, parasomnias such as sleep walking, night terrors, and enuresis, which are prevalent in children, occur within this time period (3) and, although many of these disturbances involve motoric activation, they rarely result in full behavioral arousal. Furthermore, in association with some parasomnias (e.g., enuresis) significant internal stimuli may be disregarded and sleep maintained despite negative behavioral and psychologic consequences of such unresponsiveness $(4,15)$. These disturbances occur predominantly during slow-wave (stages 3 and 4) sleep, but diminished reactivity is also characteristic of stage 2 sleep during the first sleep cycle. In adults, arousal threshold values for first cycle stage 2 sleep are increased relative to stage 2 measures taken later in the night, and in the present study half of the stage 2 attempts failed to elicit signs of behavioral or physiologic arousal. These data support and extend the previously advanced notion that sleep during this initial period may be functionally different from that during subsequent NREM cycles (8).

It has been suggested that the awakening threshold reflects an 
adaptive mechanism fundamental to sleep maintenance in the presence of stimuli which normally evoke responses during wakefulness, but which permits arousal and response to imperative stimuli $(28,36)$. Unless there is some as yet undetected peculiarity of the preadolescent age group studied in this investigation, the present data suggest that before and perhaps extending into adolescence this mechanism is either incompletely developed or is superseded by sleep maintenance mechanisms, presumably to allow an important sleep-related function to occur.

It has been postulated that sleep is a time for differentiation, maturation, and restoration of physiologic and neurochemical processes $(1,23,30,32,38)$, and the intensity at which some of these processes occurs in childhood may be related to this unusually elevated threshold to arousal. Whatever biologic priorities and functions are satisfied during the initial hours of sleep, in children it is apparently important that such activities proceed with minimal interruption. One consequence of this overriding of arousal mechanisms is a compromised capability during sleep to respond to stimuli-endogenous and exogenous-some of which may signal potentially life-threatening events e.g., respiratory distress $(10,12,13,14)$ or signals from emergency alarm devices $(21,25)$. Clearly, further investigation into factors underlying this sleep-related functional debilitation in children is warranted.

\section{REFERENCES AND NOTES}

1. Agnew, H. W. Jr. and Webb, W. B.: The displacement of stages 4 and REM sleep within a full night of sleep. Psychophysiology, 5: 142 (1968).

2. Bonnet, M. H. and Johnson, L. C.: Relationship of arousal threshold to sleep stage distribution and subjective estimates of depth and quality of sleep. Sleep, I: 161 (1978)

3. Broughton, R. J.: Sleep disorders: Disorders of arousal? Science, 159: 1070 (1968).

4. Broughton, R. J.: Childhood sleepwalking, sleep terrors and enuresis nocturna: The pathophysiology and differentiation from nocturnal epileptic seizures. In: L. Popoviciu, B. Asgian, and G. Badiu, Eds.: Sleep 1978: Fourth European Congress on Sleep Research. p. 103 (Karger, Basel, 1978).

5. Busby, K., Firestone, P., and Pivik, R. T.: Sleep patterns in hyperkinetic and normal children. Sleep, 4: 366 (1981).

6. Conners, C. K.: A teacher rating scale for use in drug studies with children. Am. J. Psychiat., I26: 884 (1969).

7. Conners, C. K.: Symptom patterns in hyperkinetic, neurotic and normal children. Child Develop., 41: 667 (1970).

8. Feinberg, I., Fein, G., and Floyd, T. C.: EEG patterns during and following extended sleep in young adults. Electroenceph. Clin. Neurophysiol., 50: 467 (1980).

9. Feinberg, I., Hibi, S., Braun, M., Cavness, C., Westerman, G., and Small, A.: Sleep amphetamine effects in MBDS and normal subjects. Arch. Gen. Psychiat., 31: 723 (1974)

10. Guilleminault, C., Peraita, R., Souquet, M., and Dement, W. C.: Apneas during sleep in infants: Possible relationship with sudden infant death syndrome. Science, 190: 677 (1975)

11. Haig, J. R., Schroeder, C. S., and Schroeder, S. R.: Effects of methylphenidate on hyperactive children's sleep. Psychopharmacology (Berlin), 39: 185 (1974).

12. Hoppenbrouwers, T., Hodgman, J. E., Arakawa, K., McGinty, D. J., Mason, J., Harper, R. M., and Sterman, M. B.: Sleep apnea as part of a sequence of events: A comparison of three months old infants at low and increased risk for sudden infant death syndrome (SIDS). Neuropaediatrie, 9: 320 (1978).

13. Hoppenbrouwers, T., Hodgman, J. E., Harper, R. M., Hofmann, E., Sterman, M. B., and McGinty, D. J.: Polygraphic studies of normal infants during the first six months of life: III. Incidence of apnea and periodic breathing. Pediatrics, 60: 418 (1977).

14. Hoppenbrouwers, T., Jensen, D. K., Hodgman, J. E., Harper, R. M., and Sterman, M. B.: The emergence of a circadian pattern in respiratory rates: Comparison between control infants and subsequent siblings of SIDS. Pediatr. Res., 14: 345 (1980).
15. Jacobson, A., Kales, J. D., and Kales, A.: Clinical and electrophysiological correlates of sleep disorders in children. In: A. Kales, Ed.: Sleep: Physiology and Pathology. p. 109 (J. B. Lippincott, Toronto, 1969).

16. Johnson, L. C., Church, M. W., Seales, D. M., and Rossiter, V. S.: Auditory arousal thresholds of good sleepers and poor sleepers with and without flurazepam. Sleep, 1: 259 (1979).

17. Johnson, L. C. and Lubin, A.: Spontaneous electrodermal activity during waking and sleeping. Psychophysiology, 3: 8 (1966).

18. Keefe, F. B., Johnson, L. C., and Hunter, E. J.: EEG and autonomic response patterns during waking and sleep stages. Psychophysiology, 18: 198 (1971).

19. Khan, A. and Rechtschaffen, A.: Sleep patterns and sleep spindles in hyperkinetic children. Sleep Res., 7: 137 (1978).

20. Murray, B. and Campbell, D.: Sleep states in the newborn: influence of sound. Neuropaediatrie, 2: 335 (1971).

21. Nober, E. H., Pierce, H., Well, A., Johnson, C. C., and Clifton, C.: Waking effectiveness of household smoke and fire detection devices. National Bureau of Standards Report (NBSIR-78-1484; HEW), 1978.

22. Ornitz, E. M., Ritvo, E. R., Panman, L. M., Lee, Y. H., Carr, E. M., and Walter, R. L.: The auditory evoked response in normal and autistic children during sleep. Electroenceph. Clin. Neurophysiol., 25: 221 (1968).

23. Oswald, I., Sleep as a restorative process: Human clues. Prog. Brain Res., 53: 279 (1980)

24. Oswald, I., Taylor, A. M., and Treisman, M.: Discriminative responses to stimulation during human sleep. Brain, 83: 440 (1960)

25. Pezoldt, V. J. and Van Cott, H. P.: Arousal from sleep by emergency alarms: Implications from the scientific literature. National Bureau of Standards Report (NBS-GCR-80-284), 1980.

26. Pisano, M., Rosadini, G., Rossi, G. F., and Zattoni, J.: Relations between threshold of arousal and electroencephalographic patterns during sleep in man. Physiol. Behav., $l$ : 55 (1966).

27. Price, L. J. and Kremen, I.: Variations in behavioral response threshold within the REM period of human sleep. Psychophysiology, 17: 133 (1980).

28. Rechtschaffen, A., Hauri, P., and Zeitlin, M.: Auditory awakening thresholds in REM and NREM sleep stages. Percept. Mot. Skills, 22: 927 (1966).

29. Rechtschaffen, A. and Kales, A., Eds.: A Manual of Standardized Terminology, Techniques, and Scoring Systems for Sleep Stages of Human Subjects. (Brain Information Service/Brain Research Institute, UCLA 1968).

30. Roffwarg, H. P., Muzio, J. N., and Dement, W. C.: Ontogenetic development of the human sleep-dream cycle. Science, 152: 603 (1966).

31. Rousey, C. L.: Auditory acuity during sleep. Psychophysiology, 16: 363 (1979).

32. Sassin, J. F., Parker, D. C., Mace, J. W., Gotlin, R. W., Johnson, L. C., and Rossman, L. G.: Human growth hormone release: Relation to slow-wave sleep and sleep-waking cycles. Science, 165: 513 (1969)

33. Schmidt, K. and Birns, B.: The behavioral arousal threshold in infant sleep as a function of time and sleep state. Child Develop., 42: 269 (1971).

34. Schubert, E. D.: Hearing: Its Function and Dysfunction. (Springer-Verlag, New York, 1980).

35. Small, A., Hibi, S., and Feinberg, I.: Effects of dextroamphetamine sulfate on EEG sleep patterns of hyperactive children. Arch. Gen. Psychiat., 25: 369 (1971).

36. Snyder, F.: The new biology of dreaming. Arch. Gen. Psychiat., 8: 381 (1963).

37. Stahl, M., Orr, W. C., and Griffiths, W. J.: Nocturnal levels of growth hormone in hyperactive children of small stature. J. Clin. Psychiat., 40: 225 (1979)

38. Valk, I. M. and Van den Bosch, J. S. G.: Intradaily variation of the human ulnar length and short term growth-a longitudinal study in eleven boys. Growth, 42: 107 (1978)

39. Watson, R. and Rechtschaffen, A.: Auditory awakening thresholds and dream recall in NREM sleep. Percept. Mot. Skills, 29: 635 (1969).

40. Williams, H. L., Hammack, J. T., Daly, R. L., Dement, W. C., and Lubin, A. Response to auditory stimulation, sleep loss and the EEG stages of sleep. Electroenceph. Clin. Neurophysiol., 16: 269 (1964).

41. Zimmerman, W. B.: Sleep mentation and auditory awakening thresholds. Psychophysiology, 6: 540 (1970).

42. The authors thank Fred Bylsma, Serge Lallier, Kathy Margittai, and Dr. Terence Picton for their technical assistance, Carole Lussier for audiometric testing, and Dr. Philip Firestone for referring hyperactive children to the study. This study was supported by grants from the Ontario Mental Health Foundation.

43. Requests for reprints should be addressed to: Dr. R. T. Pivik, Ottawa General Hospital, Department of Psychiatry, 501 Smyth Road, Ottawa, Ontario, K1H 8L6 CANADA.

44. Received for publication August 26, 1982.

45. Accepted for publication February 10, 1983. 